\title{
Sustainable development in the model of an integrated system of public education, creativity and humanistic learning
}

\author{
Yurii Tymoshenko ${ }^{1 *}$, Olha Palamarchuk $^{2}$, Mykola Iehupov $^{3}$, Tetyana Dovbenko ${ }^{4}$ \\ 'doctor history of science, associate professor of social humanities department, National University of \\ Ukraine on Physical Education and Sport, Kyiv, Ukraine. \\ ${ }^{2} \mathrm{PhD}$ in Education Sciences, Senior Researcher in Department of Quality Assurance in Higher \\ Education, Institute of Higher Education of the National Academy of Educational Sciences of \\ Ukraine, Kyiv, Ukraine. \\ ${ }^{3} \mathrm{PhD}$ in Philosophy, Associate Professor in Department on History and Theory of Olympic Sport, \\ National University of Ukraine on Physical Education and Sport, Kyiv, Ukraine. \\ ${ }^{4}$ Senior Lecturer, National University of Ukraine on Physical Education and Sport, Kyiv, Ukraine.
}

\begin{abstract}
In the context of ensuring an effective strategy for sustainable development, it is necessary to consider that modern education is mainly focused on the theoretical type of scientific knowledge, on natural and engineering-technological models of thinking. At the same time, the theory of pedagogy is constantly debated and criticized by scientism. It is a term that doesn't exist in the European countries - humanitarian or humanistic technologies - it is like wooden iron, because both the humanitarian and humanistic paradigms were formulated and spread as an alternative to the technological direction, starting from it. This is a contradiction within the theory. Another contradiction: despite the frontal critique of the school of knowledge and subject-centrism, in practice such a subject-oriented or psychologically-oriented approach remains dominant. As a result, in the minds of schoolchildren, students there is a mosaic of unrelated pieces of knowledge. Why do we hold such an approach so firmly? It is important to understand the reasons for this, otherwise we will not be able to find a practical way out of this situation, one criticism is not enough. This is not an internal pedagogical issue, but the convenience of management, external control over the activities of the education system, educational institution. Attempts to reform the pedagogical system constantly run into this circumstance, as pedagogy in its main part remains entirely state and regulated from the outside, no matter how much we talk about the partial autonomy of school, education, higher education.

The model of Waldorf pedagogy is still the only one that aims to transfer the experience of sustainable development in various fields comprehensively, that is, in its own way repeats the development of mankind in teaching. In Waldorf pedagogy, the component of responsibility is realized, for instance, through environmental education. It is necessary to perceive the activity as a part of the general activity. Freedom has a structure and necessarily includes a component of responsibility.
\end{abstract}

\section{Introduction}

What can be understood as an alternative in social development, pedagogy, philosophy of education and education management? Let's pay attention to the two main meanings of the concept of "alternative". First, the alternative is the existence of a choice, we can choose between different paths, different directions. Secondly, the concept of alternative, relevant,

\footnotetext{
${ }^{*}$ Corresponding author: dozent3000@gmail.com
} 
in particular, for education, is that there may be different pedagogical systems and directions, and these approaches are alternative to each other, and they cannot be practically combined.

Of course, you can borrow from different pedagogical systems the best individual elements and combine them. But this is not always the case. For example, the project approach in teaching, focused primarily not on knowledge but on action and aimed at forming key competencies, is very difficult to combine with the usual traditional approach, because it differs: the organization of learning, distribution of hours, the role of teacher, teacher training. Each approach in pedagogy give a number of consequences that change everything.

In teacher-centered pedagogy, the teacher is at the center of the class and teaches, standing or sitting in front of him. This entails the appropriate shape of the room - how the classroom is organized, how students sit. If we take the principle of group work, it will determine a different organization of student work, a different arrangement of tables in the classroom. It turns out that the basic principle of a particular pedagogy needs a lot of other things: the distribution of time during the day, and the form of control of the result, etc. And we can't combine them. They cannot be connected not because they are opposite, but because real time is limited and you have to choose. That is why, of course, theoretically we can talk about the connection of different alternative approaches, but in life you have to choose.

\section{Research methodology}

As for Waldorf pedagogy, it should be noted that it is the most complex in comparison with other pedagogues, such as the pedagogy of M. Montessori or the pedagogy of $\mathrm{J}$. Dewey. First of all, because it does not take as a basis any one principle, which is then carried out through the whole system and from which we can deductively deduce everything in general. For example, Montessori pedagogy is based on the idea that the child develops itself. This is an alternative to the fact that the adult from the outside, by his actions directs to read: imposes - the child, how and with what speed to develop. "Help the child to do it by himself" - the slogan of pedagogy. Didactic material is built in such a way that the child, dealing with it independently, develops in self-movement. Of course, the idea of self-development is an important idea, and it should be present in any pedagogy, but here it is carried out starting with preschoolers through the whole system as a basic principle.

Waldorf pedagogy differs from others that it counts the profound metamorphoses of human development at different ages and at different stages [1]. Depending on this, approaches change dramatically. Waldorf kindergarten is one situation, junior and secondary school are two completely different situations, and high school is a third situation. This is the first thing to consider.

The second is the methodology of individual subject areas. Here, it would seem, we can take a single methodological principle. For instance, sensory cognition and theoretical cognition - are the famous principle of developmental learning, which is conducted in all subjects. Waldorf says that each subject has its own internal logic. For example, literature (language, word, literature, history, humanities) has its own methodology. The natural direction has its own. Animate and inanimate nature have two methodologies, two different types of thought. Rudolf presents such system of sciences, and each science has its own methodology in accordance with the qualitative feature of its subject [2].

Thus, according to Waldorf pedagogy, we can talk about the pluralism of methods and methodology. When imposing the metamorphosis of age on methodological pluralism, each time there is some approach at a certain age for each subject. 


\section{Results of the research}

Apparently, it is still possible to express some fundamental principles that unite all Waldorf pedagogy into the whole. First, it is the principle of integrity, which is based on the understanding of man as a whole three-part being, "consisting" of body, soul and spirit, which determine each other, and in pedagogy act as the integrity of thinking, feeling and will.

Pedagogy is built in such a way that in the curriculum this integrity is preserved. That is, along with the cognitive or knowledge components, there are also aesthetic and practical, as separate lines of educational content [3]. Every day and in every subject, they try to involve the whole person. The lesson begins with the children entering the classroom and joining its rhythmic part - they move, read poems in chorus, especially in junior classes, sing. The rhythmic part unites the artistic element, the element of movement involved the body, imagination, creative self-expression. This happens every day, in junior classes up to 20-30 minutes. Then comes the so-called basic lesson, similar to our usual lesson. But it also has a rhythmic division, the activity of the teacher and the activity of students change each other, intense inclusion and attention, exhalation, when you can walk around the classroom, etc. It all ends with a teacher's story at the end of the lesson. It turns out that each lesson is a small artistic composition, imbued with a musical-rhythmic element.

\subsection{Is it possible to consider the picture of the world?}

Let's take geography. Geography can be described by specifying how many hours it takes as a subject. But is it possible to imagine geography without a hike, without a picture of the way from home to school - the first small map, as it is done in the Waldorf school, the first binding to the ground, when a child measures distance with his own small steps? Geography is not considered itself as a subject, but in its connection with man in development. And this is an important psychological and pedagogical principle in this case. We not only teach geography, but also contribute to the development of the child's spatial consciousness.

An alternative to this is to give a small preschooler a globe (as is the case in some other alternative pedagogies) and say: this is your land, your world in which you live. It is very cute, but it does not consider how the child experiences, sees the world from within himself. The globe - the result of millennial development of science - rises as a finished result. Waldorf educators say that there is no better way to harm a child's abilities than to offer him ready-made results of scientific knowledge. Any modern textbook is built on this principle.

It should be bear in mind that only in the middle classes the child wakes up for reality, before that he lives in the world of his imagination, he is not quite born for our subjectspatial world. But birds, slides - this is their world. The younger the child, the more important what and how he internally experiences (emotional state, interest, bad or good).

Waldorf pedagogy counts this "life world" of the child, how the child perceives and feels the world [4]. Pedagogy tries to meet child, not to pass the child under it, hanging on it "scientific concepts". Therefore, geography begins at the age when the child wakes up to this real spatial world. Subjects appear in the school curriculum in parallel with how the child begins to wake up to this world, are considered through the prism of the child's formation, through his thinking, feelings and will or body, soul and spirit. Such a psychological and pedagogical principle dominates here. The same with other items. For example, grammar is introduced only in class III, because it helps to strengthen the growing self-awareness of the child. Before that, the child is still completely merged with the language. And this is good for the child: emotionally filled, full of experience of life in 
language, which "dies" in abstract grammar. Therefore, too early teaching of grammar, according to Waldorf philosophy, is harmful to the child.

"Life world" - a term of phenomenological philosophy of Edmund Husserl - plays a crucial role in foreign theoretical pedagogy [5].

It is now mentioned in official documents issued by the German Ministry of Education as a necessary principle.

This approach, as an important component of the humanization of the school, through phenomenological pedagogy has become a recognized general pedagogical heritage. And Waldorf pedagogy shows a possible way to implement it in the practice of school teaching.

\subsection{Social education in science lessons?}

Let's take another example - mathematics. The task is given: what is 12 ? This task allows you to identify different solutions to different children, and they are all correct, for example: $6+6,5+7,3+3+3+3,4+4+4+4$, etc. There are also such "beautiful" options: 1 $+2+3+3+2+1$. That is, in addition to mathematics, moments of individualization and socialization are included. A child, as Waldorfians say, learns to understand that what another person does in different way can also be right.

So, we have social education in math lessons.

In addition, going from the whole to the parts is an "organic way of thinking," while adding the result of individual elements is mechanistic. The latter is also important, but it must be supplemented by the former - for the same integrity. This is important because the mechanistic method still dominates today and such one-sidedness can be dangerous.

And in mathematics there is a rhythm - children clap, stomp, play rhythmic number games. Here, together with thinking and feeling, corporeality ("will") and the aesthetic element ("soul") are connected.

It turns out that mathematics is needed not only for arithmetic and the development of purely cognitive abilities, but also for the development of physical, mental and spiritual health. And so, it would seem, a purely abstract thing that has nothing to do with personality. Once again, Steiner said that health is not that a person is not sick, but whether he has a healthy interaction between thinking, feelings and will [6]. An enthusiastic person is a healthier person, and a bored, "overwhelmed" theoretical "scholar", from this point of view, is unhealthy.

Such things are typical of Waldorf. Unfortunately, before Waldorf pedagogy is still, as it says, "was unexplored before". This is due to the fact that Steiner is strongly associated with religious philosophy, mysticism, and scholars usually feel a strong prejudice against such things. Of course, to understand Steiner's anthroposophy is a very difficult task. There is much that goes far beyond scientific discourse. But there is a lot that is completely within this framework. For pedagogy, philosophy and management of education it is important that it can be possible to understand without any mysticism.

\subsection{The main school - acquaintance with pre-scientific experience}

It is very difficult to formulate the tasks of the main school purely theoretically - there is no qualitative holistic concept yet. In primary school it is necessary to form basic skills for further study. And if the student can read, count, write, he is ready for further study. High school is a preparation for life.

And what is the task of the middle level? Here there is a kind of gap. And thanks to Steiner's anthropological approach, the correlation of subject areas with man, Waldorf pedagogy finds the answer to this question. All scientific disciplines, that later became science, are based on some pre-scientific primary experience. In addition to Steiner, this was also discussed by Edmund Husserl and Martin Heidegger [7]. 
And Waldorf pedagogy (so far, the only one) aims to inform the student of this experience in different areas, that is, in its own way repeats the development of mankind in teaching.

Yes, history was born from oral tradition, from storytelling. And in each lesson according to the Waldorf system, the teacher takes some time to tell. In the first grade these are fairy tales, in the second grade - legends, lives of saints, legends and fables, in the third grade - the whole Bible is retold in the main plots. Then the mythological plots of the mythology of the people in which the school is located are set out, and this line of narration flows smoothly into the history of the eastern peoples. History at its birth is immersed in a mythological element, and in the Waldorf school, history also begins with a reliance on the mythological plots of Greece. In ancient Greece, history is born, and this is the IV-V classes of the school. At what point in pre-scientific experience is science born?

The birth of history from history is an example of how science gradually crystallizes from some previous primary experience. The same is true in all other areas of knowledge. What later became physics was also, at first, some kind of primary experience. And what will become chemistry later, Waldorf people start by lighting a fire in class (watching how different substances burn).

The motive of pre-scientific experience as the basis of all sciences is one of the main motives of the philosophy of the XX-XXI centuries. It, in the person of its best representatives, resisted, struggled with the total "learning" of everything. However, Steiner did not know Husserl, as well as Heidegger. He came from Goethe, from the so-called "heteanistic" approach, a kind of desire for naturalness.

This origin of the objects of the natural cycle from the primary experience that precedes science is reconstructed in the lessons in the Waldorf system. High school is just needed to immerse yourself in this experience, which in high school leads to serious science [8].

In this smooth transition, we trace some integrity. Indeed, science can be done purely intellectually, and you can do so that a person is fully involved in it. People who were engaged in science were passionately interested in their subject, and not in abstract theorizing. Abstractness leads to the fact that a person seems to know a lot, but it makes no sense. Waldorf pedagogy is, of course, an alternative to such an "accumulative" approach.

\subsection{Disadvantages of self-actualization and pragmatism}

The concept of "self-actualization" came from humanistic psychology. If we compare the understanding of a healthy personality in Waldorf pedagogy with the self-actualizing personality according to A. Maslow [9], It should be noted that Waldorf pedagogy and Steiner - are independent phenomena that are not directly related to the concept of humanistic psychology. At the same time, there is much in common.

Among modern parents there are those who leave their children in the care of nannies for their own self-realization. This phenomenon is quite common. It is necessary to remember about limits of the principle of self-actualization and dangerous tendencies, hiding places in it. If self-actualization is taken as an end in itself, it becomes a substitute for mental and spiritual principles.

According to Waldorf "ideology", a person is among other people and life consists of a network of semantic connections. I am not just one existing and self-actualizing. I exist in a network of meaningful relationships and connections and I build them myself. Therefore, each of my actions is associated with understanding the other, with the ability to interact with them, to set common meaningful goals.

The task of high school, according to Steiner, is to develop the ability to judge independently [10]. What is a judgment? In purely human terms, judgment is the ability to apply one's abilities to something beyond me and my thinking. In logic (concept, inference, judgment) judgment is a logical operation that connects the predicate and the subject, when 
I say something about something, somehow relate to it. This interaction with the world, the connection of my thinking with the world, is a kind of freedom [11]. Waldorf pedagogy also aims to develop it. But freedom has a structure. Freedom is not just an opportunity to do something, creatively self-realizing, it has another component, which can be called "world", "social world", "world of work".

There is a good word that emphasizes this - responsibility. My freedom must be responsible, and for that I must have the ability to understand another person.

Another paradigm is pure pragmatism. That is, I will act depending on how much more for me and my company my activities will bring benefits, and then I will be successful. This is pure pragmatism. On the scale of the social whole, such a position leads to an end, because the goals of such companies and society as a whole do not always coincide.

\subsection{Creativity, or about a "healthy personality"}

In Waldorf pedagogy, the component of responsibility is realized, for example, through environmental education. It is necessary to perceive the activity as a part of the general activity. Of course, I have to be good, I have to earn well, but if it destroys the environment and harm others, it is not a success. Freedom has a structure and necessarily includes a component of responsibility [12].

Why, thinking about alternative approaches to Waldorf pedagogy, we again come to the issue of personality? Is not it because any pedagogical system inevitably contains it, even if it is not specifically stated? It is impossible to depart completely from the concepts of personality, which we directly or indirectly form, hiding behind methodological schemes and developments. Sooner or later, it will attract attention and may require another review.

\subsection{Pedagogy - a consequence of the type of management and model of social development?}

Modern education is mainly focused on the theoretical type of scientific knowledge, on natural and engineering-technological models of thinking. At the same time, the theory of pedagogy is constantly debated and criticized by scientism. There is a term that doesn't exist in the European country - humanitarian or humanistic technologies - it is like wooden iron, because both the humanitarian and humanistic paradigms were formulated and spread as an alternative to the technological direction, starting from it. This is a contradiction within the theory.

Another contradiction: despite the frontal critique of the school of knowledge and subject-centrism, in practice such a subject-oriented or psychologically-oriented approach remains dominant. As a result, in the minds of schoolchildren, students there is a mosaic of unrelated pieces of knowledge. Why do we hold such an approach so firmly? It is important to understand the reasons for this, otherwise we will not be able to find a practical way out of this situation, one criticism is not enough. Most likely the reason is that this type of knowledge pedagogy is easier to control, describe and operationalize.

You can safely call a schoolboy, a student to the board, extract from him what he has learned, or give him a test, to conduct certification, accreditation. This type of pedagogy is easier to manage. It is convenient for the state structure. This is not an internal pedagogical issue, but the convenience of management, external control over the activities of the education system, educational institution. Attempts to reform the pedagogical system constantly run into this circumstance, as pedagogy in its main part remains entirely state and regulated from the outside, no matter how much we talk about the partial autonomy of school, education, higher education.

In Waldorf pedagogy there is a provision that the school should be a certain autonomous self-governing unit in the system of the social whole, because the most important thing in pedagogy is exactly what remains behind the scenes in external control, 
which is difficult to formalize and operationalize [13]. However, this does not mean that I do what I want, the complete absence of any state control. It is necessary to create alternative ways of evolution - expert assessment of school activities - and only under this condition is it possible to change the one-sided knowledge orientation of the school. Theory can do little to help, because in theory, that is, on paper, all these problems can be solved quite easily, and then reasonably say that science is not responsible for the fact that practitioners do not use the results of research and development.

\subsection{Purposeful formation of the "hunger for knowledge"}

It is known that the quota of university entrants for students of Waldorf schools is 2-3 times higher than for regular schools. And this is a mystery for pedagogical science. There are various explanations for this. For example, in the West, parents who have an increased interest in their children's education send their children to Waldorf schools.

The Waldorfians themselves give a different explanation. If at the beginning of learning children do not overload, but go through the integrity of experience, then their interest and taste for thinking and knowledge do not disappear [14]. On the contrary, if you hold the student a little, he develops a "hunger", a constant "hunger" for knowledge, and this desire to learn develops and continues constantly.

This is a very modern approach, as more and more people are now talking about lifelong learning. Waldorf people claim that due to the fact that they awaken the hunger for knowledge, not "overfeeding" in the younger stages and in high school, that is, they act by awakening the "cognitive hunger" through motivation, they form a constant desire for knowledge, thirst for knowledge.

\subsection{What do we expect in the results}

The declared goal of Waldorf pedagogy is a healthy personality, according to Steiner, "a full-fledged person" [15]. In knowledge pedagogy, the goal is a person who has knowledge. Why? Because knowledge itself equips people to rework the world, to solve the problems facing "humanity". So, it was necessary, they say, to arm it, roughly speaking, with knowledge, and then, look, it will cope with the problems that exist in the natural and social world. This is the basic paradigm of the whole epoch, the science of the New Age.

Waldorf pedagogy is arranged differently. It argues that the student at the exit should be a healthy, full-fledged person. And health is understood here not only as physical. Obtaining scientific knowledge is only one and perhaps not the most important moment for human life as a whole.

A person is not only an active figure who reworks and transcends the "spaces of the universe", but also a father, a mother who starts a family and raises children, a person who, in addition to working days, also has days off, not to mention evenings, a person with broad or narrow interests, etc. It is not knowledge and scientific concepts that are important in themselves, but how the concept - thinking - is built into the whole person. Is thinking interested, "participatory" thinking or not? Does beauty give a person joy? Is a person able to bring the case to an end? Is its psychosomatic base resistant to stress and overload? Active activity in the world, science - yes! But it all depends on who, that is, what kind of person, operates in the world or is engaged in science. The individual is thus more primary than "humanity" and "scientific and technological progress."

Human health is so different from health, which involves a harmonious combination of body, soul and spirit, rather than their opposition, which leads to various neuroses and psychosomatic disorders [16]. Therefore, it is important to work out and strengthen these interrelationships between disparate elements, and not to bring health into a separate health program that corrects unhealthy pedagogy in itself. Therefore, for example, in Waldorf physical exercises connected with imagination, adventures, with display of emotions. And 
it turns out that through physical education we go to all three areas, although, of course, in physical education the emphasis is on physical development. And each subject in its own way works for a whole, healthy person.

Recall the slogan of Francis Bacon: "Knowledge is power!". This approach to the world as a place of transformative human activity through scientific knowledge is a very powerful historical paradigm. It still lives in many minds. It is very strong in the ideology of developmental learning and is still the main, often unconscious foundation in domestic education and school in general. There are, of course, other things, but this is the main one. Within the framework of the basic philosophical premise the philosophy of pedagogy also develops: to create the theory for effective management of development of the person. These are all different versions of the basic Bacon paradigm.

\section{Conclusion}

Nobody says that in our education system everything is state-owned and there is no creativity and cannot be. But still the pedagogical process is built in such a way that creativity, if it happens, is rather contrary to the system. Constant checks, control over why the lion's share of attention is paid, are unlikely to promote creative self-expression.

The pathos of the three-component model is that the body, soul, spirit are interconnected. A person who lives a creative meaningful life is physically healthier. Such person is less tired and can withstand stress. The integrity of a healthy personality can be divided into a spiritual component, for the ability to creatively comprehend the independent actions of life and set goals, and mental (or emotional) resilience. To become a doctor, you have to take many different steps - to enter the institute, to prepare for exams. The fact that you can endure and go through all this is my emotional stability and mental health. By the way, this fits perfectly into the theory of activity and once again confirms that different theories can describe the same thing in different conceptual languages.

If we take a three-component model of personality (body, soul, spirit), then the spirit in this case - this is the creative beginning. It is possible to tell differently: spirit is some ability to a meaningful creative life. This must be distinguished from self-actualization in the tradition of humanistic psychology. After all, you do not just create and self-realize in general, in some empty space (involuntarily mentions creative freedom, where freedom is a creative act without foundation, "out of nothing"). What you create must have some significance for another. Freedom is not a creation in emptiness. This is an act based on understanding, such as a responsible act.

This is the difference. A person, a certain specialist, can simply work his hours at his workplace, but such an employee is no longer suitable for a modern high-tech and efficient company. A person should do his job with pleasure, approach it creatively and be successful. This is characteristic of a spiritually healthy person. To engage in meaningless work is harmful to both the individual and health. A person can do the same work with different content. Someone does his job with pleasure, because he sees the point in it - his actions are accompanied by a sense of understanding of life and their activities. And for another - it's routine work, the cross he carries.

If a person approaches his life with the philosophy of carrying the cross, it will turn into a cross. And if a person is able to see the meaning in a seemingly routine lesson, he has a certain excess of mental health. If a person is constantly in a state of stress, forcing himself, doing everything out of a sense of duty, then in the long run it will harm his health, including physical, as well as success in professional activities, which affects the profit or loss the company in which he or she works. These qualities of the employee as a holistic person, beyond professional qualifications, but which play a crucial role in professional activities, came to be called key qualifications, or competencies. 


\section{References}

1. Zdražil, T. (2019). The Understanding of Human Being in Waldorf Education across the World's Diverse Cultures. Stuttgart: Verlag Pädagogische Forschungsstelle, 152 p.

2. Steiner, R. (1994). How to Know Higher Worlds: A Modern Path of Initiation (Classics in Anthroposophy). Anthroposophic Press, 259 p.

3. Easton, F. (1997). Educating the whole child, head, heart, and hands: Learning from the Waldorf experience. Theory into Practice, 36 (2), 87-94. doi: 10.1080/00405849709543751.S2CID55665652

4. Uhrmacher, P.B. (1995). Uncommon Schooling: A Historical Look at Rudolf Steiner, Anthroposophy, and Waldorf Education. Curriculum Inquiry, 25 (4), 381406. doi: 10.2307 / 1180016. JSTOR 1180016.

5. Husserl, E. (1970). The Crisis of European Sciences and Transcendental Phenomenology: An Introduction to Phenomenological Philosophy. Evanston, Illinois: Northwestern University Press. 405 p.

6. Steiner, R. (2021). Im Urbeginn war das Wort. Rudolf Steiner Ausgaben; 2nd Edition. 256 p. P. 69.

7. Glazebrook, T. (2013). Heidegger on Science. New York: State University of New York Press, 328 p. pp. 76-77.

8. Kern, H., Zdražil, T., \& Götte, W.M. (2018). Teaching for Waldorf schools. Become an educator. Pädagogische Fragen waldorf-specifisch angehen. Frankfurt: Beltz, 384 p., pp. 112-113.

9. Maslow, A. (2017). Motivation and Personality. Scotland: HarperCollins Publishers. 293 p.

10. Paull, J. (2011) Rudolf Steiner and the Oxford Conference: The Birth of Waldorf Education in Britain. European Journal of Educational Studies, 3 (1), 53-66.

11. Steiner, R. (2021). Die Philosophie der Freiheit: Grundzüge einer modernen Weltanschauung. Seelische Beobachtungsreslete nach naturwissenschaftlicher Methode, $285 \mathrm{p}$.

12. Miller, R. (1995). Freedom in a holistic context. Holistic Education Review, 8 (3), 4-11.

13. Zdražil T., \& Lutzker P. (2019). Trains for the general public Rudolf Steiners. Scientific, artistic and scholastic perspectives. Stuttgart: Pädagogische Forschungsstelle, $416 \mathrm{p}$.

14. Paull, J., \& Hennig, B. (2020). Rudolf Steiner Education and Waldorf Schools: Centenary World Maps of the Global Diffusion of "The School of the Future". Journal of Social Sciences and Humanities, 6 (1), 24-33.

15. Oberski, I. (2006). Learning to Think in Steiner-Waldorf Schools. Journal of Cognitive Education and Psychology, 5 (3), 336-349. doi: 10.1891 / 194589506787382431 . S2CID 144940637.

16. Goldshmidt, G. (February 2017). Waldorf Education as Spiritual Education. Religion \& Education. 44 (3), 346-363. doi: 10.1080 / 15507394.2017.1294400. S2CID 151518278 